\title{
Correction to: Preclinical Biokinetic Modelling of Tc-99m Radiophamaceuticals Obtained from Semi-Automatic Image Processing
}

\author{
Luz G. Cornejo-Aragón ${ }^{1,2}$ - Clara L. Santos-Cuevas ${ }^{2}$ - Blanca E. Ocampo-García ${ }^{2}$ - Isaac Chairez-Oria ${ }^{3}$. \\ Lorenza Diaz-Nieto ${ }^{4}$. Janice García-Quiroz ${ }^{4}$
}

Published online: 9 February 2018

(c) Taiwanese Society of Biomedical Engineering 2018

\section{Correction to: J. Med. Biol. Eng. (2017) 37:887-898 https://doi.org/10.1007/s40846-017-0250-4}

The article "Preclinical Biokinetic Modelling of Tc-99m Radiophamaceuticals Obtained from Semi-Automatic Image Processing", written by Luz G. Cornejo-Aragón, Clara L. Santos-Cuevas, Blanca E. Ocampo-García, Isaac ChairezOria, Lorenza Diaz-Nieto, Janice García-Quiroz was originally published Online First without open access. After publication in volume [37], issue [6], page [887-898] the author decided to opt for Open Choice and to make the article an open access publication. Therefore, the copyright of the article has been changed to (C) The Author(s) [2018] and the article is forthwith distributed under the terms of the Creative Commons Attribution 4.0 International License (http:// creativecommons.org/licenses/by/4.0/), which permits use, duplication, adaptation, distribution and reproduction in any medium or format, as long as you give appropriate credit to the original author(s) and the source, provide a link to the Creative Commons license, and indicate if changes were made.
The original article can be found online at https://doi.org/10.1007/ s40846-017-0250-4.

Clara L. Santos-Cuevas

clara_letici@yahoo.com.mx; clara.cuevas@inin.gob.mx

Luz G. Cornejo-Aragón

lgrindelia@hotmail.com

Blanca E. Ocampo-García

blanca.ocampo@inin.gob.mx

Isaac Chairez-Oria

isaac_chairez@yahoo.com

Lorenza Diaz-Nieto

lorenzadiaz@gmail.com

Janice García-Quiroz

alexeyjagarqui@hotmail.com
1 Instituto Nacional de Investigaciones Nucleares (ININ), 52750 Ocoyoacac, Estado de México, Mexico

2 Facultad de Medicina, Universidad Autónoma del Estado de México, 50180 Toluca, Estado de México, Mexico

3 Unidad Profesional Interdisciplinaria de Biotecnología (UPIBI), Instituto Politécnico Nacional (IPN), 07340 Gustavo A. Madero, D.F., Mexico

4 Departamento de Biología de la Reproducción, Instituto Nacional de Ciencias Médicas y Nutrición Salvador Zubirán, 14080 Tlalpan, D.F., Mexico 